\title{
Dissolution of Ferrous Alloys into Molten Pure Aluminium under Forced Flow*
}

\author{
By Mitsuo Niinomi**, Yukinao Suzuki*** and Yoshisada Ueda****
}

\begin{abstract}
Commercially pure iron, $\mathrm{S} 45 \mathrm{C}, \mathrm{Fe}-\mathrm{Cr}, \mathrm{Fe}-\mathrm{Si}$ and $\mathrm{Fe}-\mathrm{C}$ alloys were dipped into molten aluminium $(99.8 \%)$ mostly at $1073 \mathrm{~K}$ and rotated at various speeds for various times. Then an alloy layer formed on each alloy was examined, and the dissolution process of these alloys was studied. The thickness of the alloy layers became thinner with increasing rotating speed. With regard to the composition of the alloy layers, $\mathrm{Fe}_{2} \mathrm{Al}_{5}$ occupied the major portion in the same manner as under the static condition. The shape of the alloy layers formed on commercially pure iron, $\mathrm{Fe}-\mathrm{Cr}$ and $\mathrm{Fe}-\mathrm{Si}$ alloys changed from tongue-like to band-like, as the rotating speed increased. For $\mathrm{Fe}-\mathrm{C}$ alloy, the alloy layer is band-like at every rotating speed.

The dissolution rate of each alloy layer increased, as the rotating speed increased. As under the static condition, the dissolution resistance against molten aluminium is the highest in $\mathrm{Fe}-\mathrm{C}$ alloy and the lowest in $\mathrm{Fe}-\mathrm{Si}$ alloy. The dissolution process of commercially pure iron, $\mathrm{S} 45 \mathrm{C}, \mathrm{Fe}-\mathrm{Cr}$ and $\mathrm{Fe}-\mathrm{Si}$ alloys is controlled by the diffusion of $\mathrm{Fe}$ in molten aluminium. Moreover, in commercially pure iron, $\mathrm{Fe}-\mathrm{Cr}$ and $\mathrm{Fe}-\mathrm{Si}$ alloys, the dissolution is accelerated by natural convection and flaking of the alloy layer at lower rotating speed, while, at higher rotating speed, it is accelerated by flaking of the alloy layer and mechanical erosion due to molten aluminium or by turblent flow near the rugged surface of alloys. The dissolution of $\mathrm{Fe}-\mathrm{C}$ alloy, however, was controlled by the chemical reaction or mass transfer in the alloy layer and the diffusion of $\mathrm{Fe}$ in molten aluminium.
\end{abstract}

(Received September 28, 1983)

\begin{abstract}
Keyzerds: resistance against molten aluminium, dissolution process, forced flow, ferrous alloy, $\mathrm{Fe}_{2} \mathrm{Al}_{5}, \mathrm{FeAl}_{3}$, mass transfer, erosion
\end{abstract}

\section{Introduction}

The dissolution of various ferrous alloys into static molten aluminium bath has been studied fundamentally, in order to obtain a ferrous alloy with high resistance against molten aluminium $^{(1)-(3)}$. In melting and casting processes of aluminium, however, ferrous alloys are often in contact with flowing molten aluminium. Hence, the corrosion of ferrous alloy by molten aluminium under the forced flow must be discussed in detail.

As a model, the investigation on the dissolu-

* This paper was originally published in Japanese in J. Japan Inst. Metals, 45 (1981), 416.

** School of Production Systems Engineering, Toyohashi University of Technology, Toyohashi 440, Japan.

*** Japan Nuclear Fuel Co. Ltd., Yokohama 239, Japan.

**** Department of Metallurgy, Faculty of Engineering, Nagoya University, Nagoya 464, Japan. tion of ferrous alloys by rotating cylindrical specimens in molten aluminium can be considered. Concerning the dissolution of solid metal into molten metal, many studies have been performed with the solid $\mathrm{Fe}-\mathrm{C}$ alloyliquid $\mathrm{Fe}-\mathrm{C}$ alloy system ${ }^{(4)-(8)}$, but few with the alloy system in this study(5)(9)(10). Moreover, the study using ferrous alloys of various compositions for solid metal was very few.

In the present investigation, commercially pure iron, $\mathrm{Fe}-\mathrm{C}, \mathrm{Fe}-\mathrm{Si}$ and $\mathrm{Fe}-\mathrm{Cr}$ alloys were dipped into molten pure aluminium and rotated at various speeds for various times, and then the effect of the forced flow on the dissolution of ferrous alloys into molten aluminium was studied.

\section{Experimental Procedure}

\section{Dipping and rotating of ferrous alloys}

Various ferrous alloys were prepared in the same manner as in a previous report ${ }^{(1)}$. The composition of these alloys is shown in Table 1. 
Table 1 Chemical composition of specimens (mass $\%$ ).

\begin{tabular}{|c|c|c|c|c|c|c|}
\hline Specimen & $\mathrm{C}$ & $\mathrm{Si}$ & $\mathrm{Mn}$ & $\mathbf{P}$ & $\mathrm{S}$ & $\mathrm{Cr}$ \\
\hline $\begin{array}{l}\text { Commercially } \\
\text { pure iron }\end{array}$ & 0.01 & 0.20 & 0.22 & 0.014 & 0.009 & - \\
\hline $\mathrm{Fe}-3 \mathrm{C}$ & 2.94 & 0.24 & 0.23 & 0.018 & 0.004 & - \\
\hline $\mathrm{Fe}-3 \mathrm{Si}$ & 0.033 & 2.91 & 0.22 & 0.002 & 0.005 & - \\
\hline $\mathrm{Fe}-3 \mathrm{Cr}$ & 0.009 & 0.15 & 0.18 & 0.001 & 0.006 & 2.94 \\
\hline $\mathrm{S} 45 \mathrm{C}$ & 0.43 & 0.25 & 0.80 & 0.008 & 0.023 & - \\
\hline
\end{tabular}

The specimen was attached to a rotator of changeable speed, dipped constantly by $0.03 \mathrm{~m}$ in depth in the center of molten pure aluminium bath $(0.35 \mathrm{~kg})$ at $1073 \mathrm{~K}$, then took out and air cooled. The rotating speed and the dipping time were variable.

The dipping was also performed at 1023 and $973 \mathrm{~K}$ for only commercially pure iron. Commercial S45C which has low carbon content was also dipped at $1073 \mathrm{~K}$, because the alloys except $\mathrm{Fe}-\mathrm{C}$ showed a rugged surface as mentioned later.

\section{Measurement of the thickness of the alloy layers}

The dipping regions of the specimens were cut out with a microcutter and embeded in resin. Thereafter, the thickness of the alloy layers was measured in the same manner as in the previous paper ${ }^{(1)}$.

\section{Measurement of the diameter of the specimens and calculation of the corrected diameter}

The diameter of the specimens was measured in the same manner as in the previous paper ${ }^{(1)}$. Since the dipped and rotated specimens showed the rugged surface generally in this work, the diameter of the specimens was estimated from the average diameter of the upper and lower halves of the dipped specimens. That is to say, the diameter was calculated by the following equations:

$$
d_{\mathrm{I}}=2 \sqrt{W_{\mathrm{I}} / \pi L_{\mathrm{I}} \rho_{\mathrm{s}}}, \quad d_{\mathrm{II}}=2 \sqrt{W_{\mathrm{II}} / \pi L_{\mathrm{II}} \rho_{\mathrm{s}}}
$$

and

$$
d=\left(d_{\mathrm{I}}+d_{\mathrm{II}}\right) / 2,
$$

where

$d_{\mathrm{I}}, d_{\mathrm{II}}:$ average diameters of the upper or lower halves of the specimen (m)

$W_{\mathrm{I}}, W_{\mathrm{II}}$ : weight of the upper or lower half of the specimen $(\mathrm{kg})$

$L_{\mathrm{I}}, L_{\mathrm{II}}:$ length of the upper or lower half of the specimen $(\mathrm{m})$

$\rho_{\mathrm{s}}$ : density of the ferrous alloy measured previously $\left(\mathrm{kg} / \mathrm{m}^{3}\right)$

and

$d$ : average diameter of the specimen (m)

These calculated average diameters $(d)$ were corrected for the weight $W_{\mathrm{I}}$ and $W_{\mathrm{II}}{ }^{(1)}$ on the assumption that $\mathrm{Fe}_{2} \mathrm{Al}_{5}$ occupied the whole alloy layer, because $\mathrm{Fe}_{2} \mathrm{Al}_{5}$ occupied the major portion of the alloy layer in this work as in the static bath ${ }^{(1)}$, as is mentioned later.

\section{X-ray diffraction analysis and hardness measurement of the alloy layers}

For X-ray diffraction analysis, a rod sample $0.01 \mathrm{~m}$ in length was cut out from the dipped and rotated specimen. For EPMA analysis and hardness measurement, the remainder of the specimen was used. The subsequent procedure was carried out in the same manner as in the previous paper ${ }^{(1)}$.

\section{Experimental Results and Discussion}

\section{Composition of the alloy layer formed on each ferrous alloy}

Figure 1 shows typical X-ray diffraction patterns of the alloy layer formed on $\mathrm{Fe}-3 \mathrm{Cr}$ alloy rotated at $2.67 \mathrm{~s}^{-1}$. These patterns are almost in agreement with those of the alloy layer under the static condition ${ }^{(1)}$.

EPMA analysis in the center of the alloy layer showed a little change in intensity of $\mathrm{Fe}-$ and Al-K lines, but this change did not exceed the 


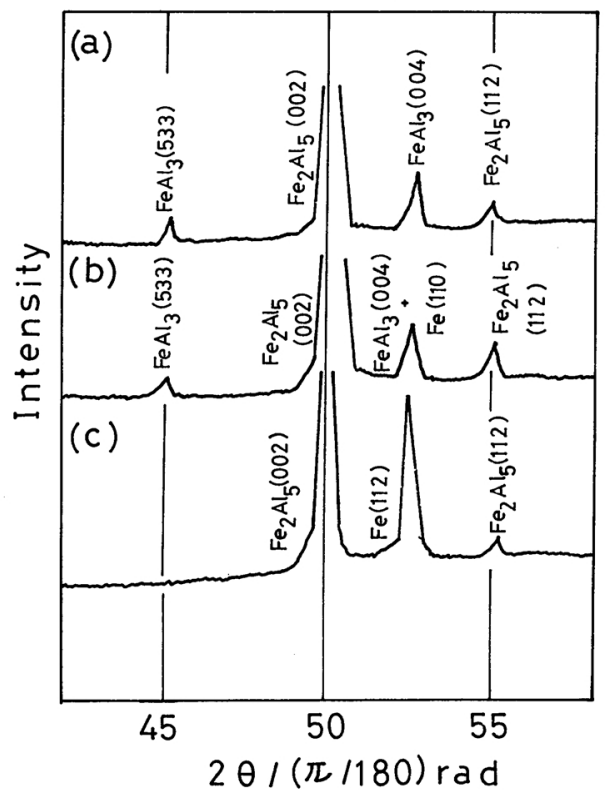

Fig. 1 X-ray diffraction patterns $(\mathrm{Fe}-3 \mathrm{Cr}$ alloy rotated at $2.67 \mathrm{~s}^{-1}$ in molten pure aluminium at $1073 \mathrm{~K})$.

(a) Surface of the alloy layer.

(b) Center of the alloy layer.

(c) Alloy layer near the base iron.

Table $2 \mathrm{Al} /(\mathrm{Fe} \cdot \mathrm{M})$ atomic ratio of the alloy layer obtained by EPMA analysis.

\begin{tabular}{|c|c|c|}
\hline \multirow{2}{*}{$\begin{array}{l}\text { Specimens, Dipping temp. } \\
\text { Rotating speed, } \\
\text { Dipping time }\end{array}$} & \multicolumn{2}{|c|}{$\mathrm{Al} /(\mathrm{Fe} \cdot \mathrm{M})$} \\
\hline & $\begin{array}{l}\text { Under } \\
\text { the forced } \\
\text { flow }\end{array}$ & $\begin{array}{l}\text { Under the } \\
\text { static(i) } \\
\text { condition }\end{array}$ \\
\hline
\end{tabular}

Commercially pure iron, $1073 \mathrm{~K}$,

$2.63 \mathrm{~s}^{-1}, 0.6 \mathrm{ks}$

2.2

Commercially pure iron, $1073 \mathrm{~K}$,

$5.18 \mathrm{~s}^{-1}, 0.9 \mathrm{ks}$

Commercially pure iron, $973 \mathrm{~K}$,

$2.67 \mathrm{~s}^{-1}, 1.5 \mathrm{ks}$

2.5

Commercially pure iron, $973 \mathrm{~K}$, $4.72 \mathrm{~s}^{-1}, 1.2 \mathrm{ks}$ $\mathrm{Fe}-3 \mathrm{C}, 1073 \mathrm{~K}$,

$2.63 \mathrm{~s}^{-1}, 1.2 \mathrm{ks} \quad \mathrm{Fe}-3 \mathrm{C}, 1073 \mathrm{~K}$,

$5.22 \mathrm{~s}^{-1}, 1.2 \mathrm{ks} \mathrm{Fe}-3 \mathrm{Cr}, 1073 \mathrm{~K}$,

$2.67 \mathrm{~s}^{-1}, 0.6 \mathrm{ks} \mathrm{Fe}-3 \mathrm{Cr}, 1073 \mathrm{~K}$,

$4.72 \mathrm{~s}^{-1}, 0.9 \mathrm{ks} \quad \mathrm{Fe}-3 \mathrm{Si}, 1073 \mathrm{~K}$,

2.2

2.4

2.4

$2.4-2.5$

$\dagger$ In the case of static condition, the dipping time differs from that in the case of forced flow. limit within which the concentrations could be considered almost constant. Therefore, Al/ $(\mathrm{Fe} \cdot \mathrm{M})$ atomic ratios $(\mathrm{M}$ : the third element) of the alloy layers, obtained in the same manner as in the previous paper ${ }^{(1)}$, are given in Table 2 with those under the static condition. These values are in the range from $\mathrm{FeAl}_{3}$ to $\mathrm{Fe}_{2} \mathrm{Al}_{5}$ phases which exist at room temperature in the $\mathrm{Fe}-\mathrm{Al}$ phase diagram ${ }^{(11)}$. Most values indicate $\mathrm{Fe}_{2} \mathrm{Al}_{5}$ phase. The distribution of alloying elements dissolved into the alloy layers was examined by EPMA line analysis. It was found that $\mathrm{Cr}$ was dissolved to some extent in the alloy layer of $\mathrm{Fe}-3 \mathrm{Cr}$ alloy.

Hardness measurement indicated that the hardness of the alloy layer almost coincided with that of $\mathrm{FeAl}_{3}$ to $\mathrm{Fe}_{2} \mathrm{Al}_{5}$ phase ${ }^{(12)}$.

These results are almost in agreement with those in the static bath. The alloy layer formed on each ferrous alloy is mostly $\mathrm{FeAl}_{3}$ near the base metal, while $\mathrm{Fe}_{2} \mathrm{Al}_{5}$ occupied the major portion of the alloy layer.

\section{Metallographic observation of the alloy layers}

In the static pure aluminium bath ${ }^{(1)}$, the alloy layers formed on commercially pure iron, $\mathrm{Fe}-3 \mathrm{Cr}$ and $\mathrm{Fe}-3 \mathrm{Si}$ alloys were markedly tongue-like, and that formed on $\mathrm{Fe}-3 \mathrm{C}$ alloy was almost band-like and slightly tongue-like at the tip. However, under the forced flow, as shown in Fig. 2 and Fig. 3, the alloy layers on commercially pure iron, $\mathrm{Fe}-3 \mathrm{Cr}$ and $\mathrm{Fe}-3 \mathrm{Si}$ alloys changed from tongue-like to band-like, as the rotating speed increased. The alloy layer on $\mathrm{Fe}-3 \mathrm{Si}$ alloy approached the band-like shape at a rotating speed lower than those for commercially pure iron and $\mathrm{Fe}-3 \mathrm{Cr}$ alloy. For $\mathrm{Fe}-3 \mathrm{C}$ alloy, the shape of the layer did not change and was band-like similar to that in the static condition, even if the rotating speed increased.

For the static bath, a narrow range of $\mathrm{Fe}-\mathrm{Al}$ solid solution existed inside the tongue-like $\mathrm{Fe}_{2} \mathrm{Al}_{5}$ phase in commercially pure iron, $\mathrm{Fe}-3 \mathrm{Cr}$ and $\mathrm{Fe}-3 \mathrm{Si}$ alloys. Such a solid solution was also observed at lower rotating speed, but not at higher rotating speed.

The shape of the alloy layer near the adhering 

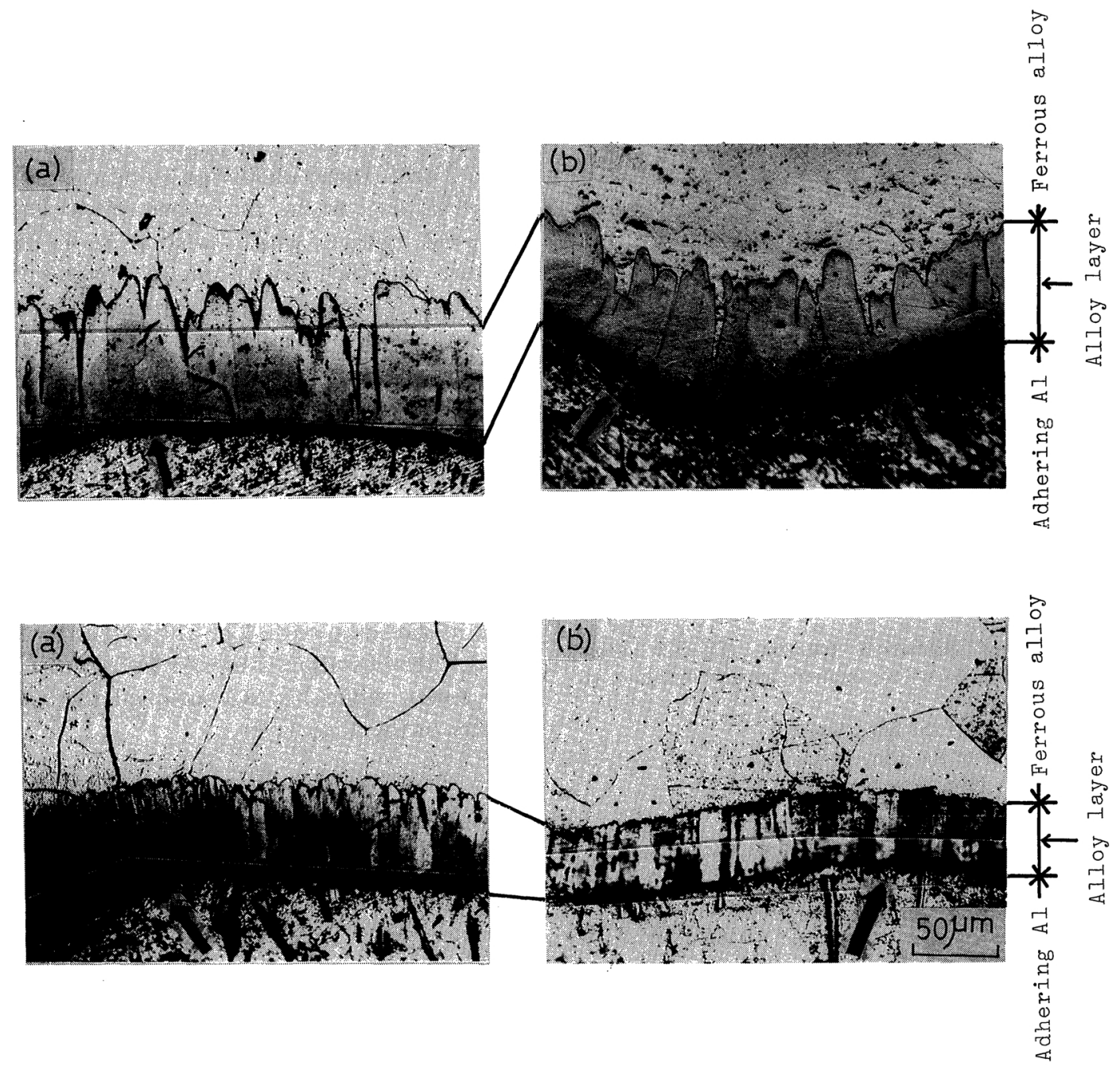

Fig. 2 Alloy layers formed on commercially pure iron and $\mathrm{Fe}-3 \mathrm{Cr}$ alloy rotated in molten pure aluminium at $1073 \mathrm{~K}$.

(a) Commercially pure iron, rotated at $2.63 \mathrm{~s}^{-1}$ for $600 \mathrm{~s}$.

(a') Commercially pure iron, rotated at $13.63 \mathrm{~s}^{-1}$ for $300 \mathrm{~s}$.

(b) $\mathrm{Fe}-3 \mathrm{Cr}$ alloy, rotated at $2.67 \mathrm{~s}^{-1}$ for $300 \mathrm{~s}$.

(b') $\mathrm{Fe}-3 \mathrm{Cr}$ alloy, rotated at $13.63 \mathrm{~s}^{-1}$ for $300 \mathrm{~s}$.

aluminium was flat in the static bath, but rugged for the rotated specimens, as shown by the arrow in Fig. 1 and Fig. 2. The rugged shape may be an evidence of flaking of the alloy layer. However, this phenomenon cannot be observed for $\mathrm{Fe}-3 \mathrm{C}$ alloy.

\section{Growth of the alloy layers}

Figure 4 shows the relation between the thickness of the alloy layer and the dipping time for commercially pure iron as a typical example.
The thickness of the alloy layers decreased with increasing rotating speed for almost all specimens. The tendency that the thickness increases with dipping time as observed in the static bath ${ }^{(1)}$ could not be observed.

The differences in the thickness of the alloy layers among the specimens, and among the temperatures for commercially pure iron are shown in Fig. 5 at rotating speed of $2.67 \mathrm{~s}^{-1}$. The alloy layer of $\mathrm{Fe}-3 \mathrm{Si}$ alloy was considerably thinner than the other alloys. The difference 

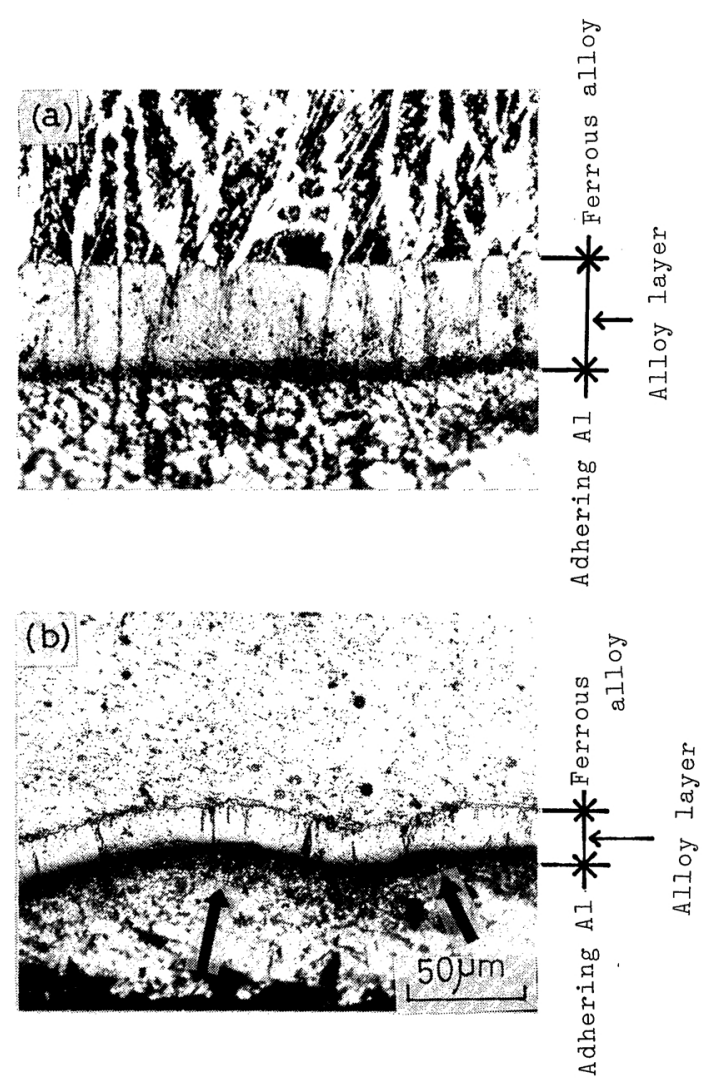

Fig. 3 Alloy layers formed on $\mathrm{Fe}-3 \mathrm{C}$ and $\mathrm{Fe}-3 \mathrm{Si}$ alloys rotated in molten pure aluminium at $1073 \mathrm{~K}$.

(a) $\mathrm{Fe}-3 \mathrm{C}$ alloy, rotated at $2.67 \mathrm{~s}^{-1}$ for $1200 \mathrm{~s}$.

(b) Fe-3Si alloy, rotated at $2.67 \mathrm{~s}^{-1}$ for $600 \mathrm{~s}$.

among the other alloys, however, was rather small in comparison with the large difference observed in the case of static bath ${ }^{(1)}$. The difference in the thickness of the alloy layers among temperatures for commercially pure iron could be hardly observed at the same rotating speed.

When ferrous alloys are rotated, the amount of dissolution increases as mentioned later. As a result, the alloy layers become thinner and approach the band-like shape. Moreover, for commercially pure iron and $\mathrm{Fe}-\mathrm{Si}$ alloy, the decrease of the thickness of the alloy layer may be enhanced by flaking.

\section{Decreasing amount of the corrected diameter of ferrous alloys}

Figure 6 shows the change in the corrected diameter with dipping time and rotating speed for $\mathrm{Fe}-3 \mathrm{Cr}$ alloy, where the result under the

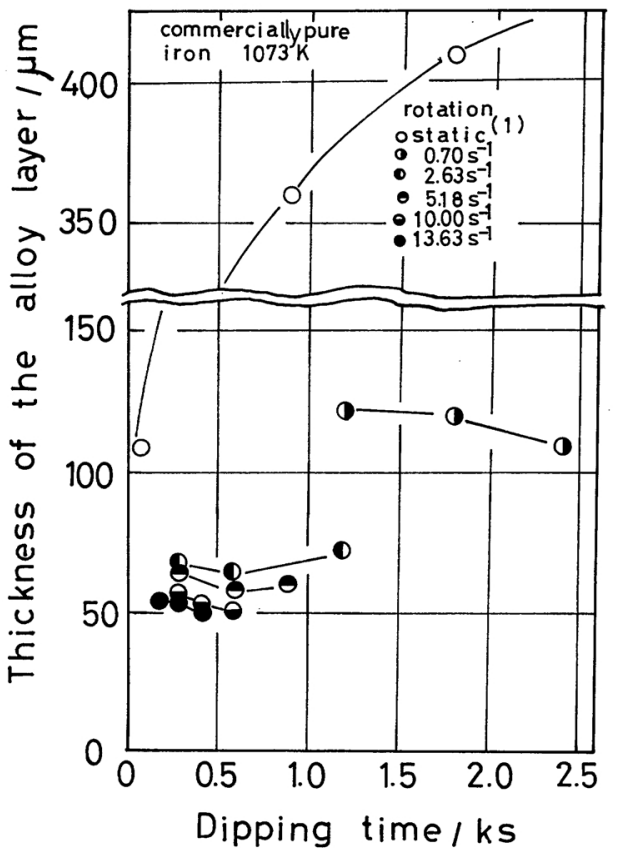

Fig. 4 Relation between thickness of the alloy layer and dipping time.

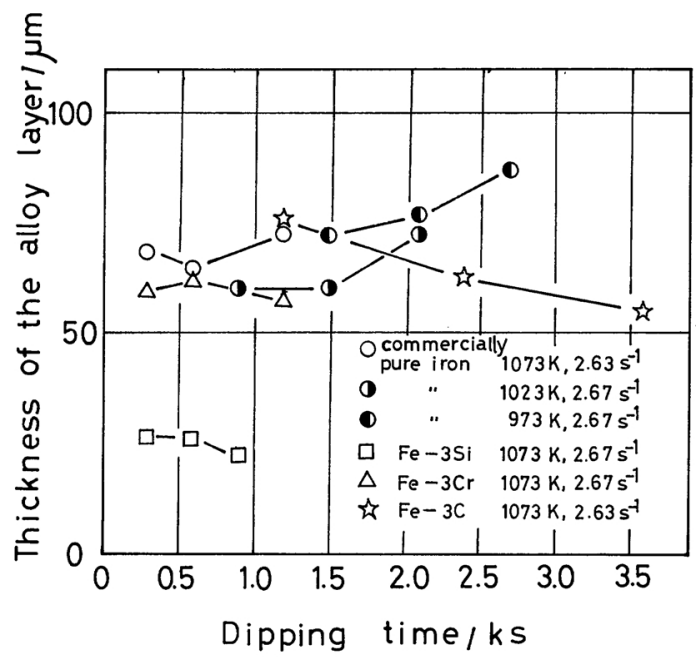

Fig. 5 Relation between thickness of the alloy layer and dipping time and temperature.

static pure Al-bath is added. The decreasing amount of the corrected diameter of ferrous alloys increases, as the rotating speed increases linearly with dipping time. But, in the static bath, the corrected diameter decreased linearly with dipping time only for Fe-3Si alloy. 


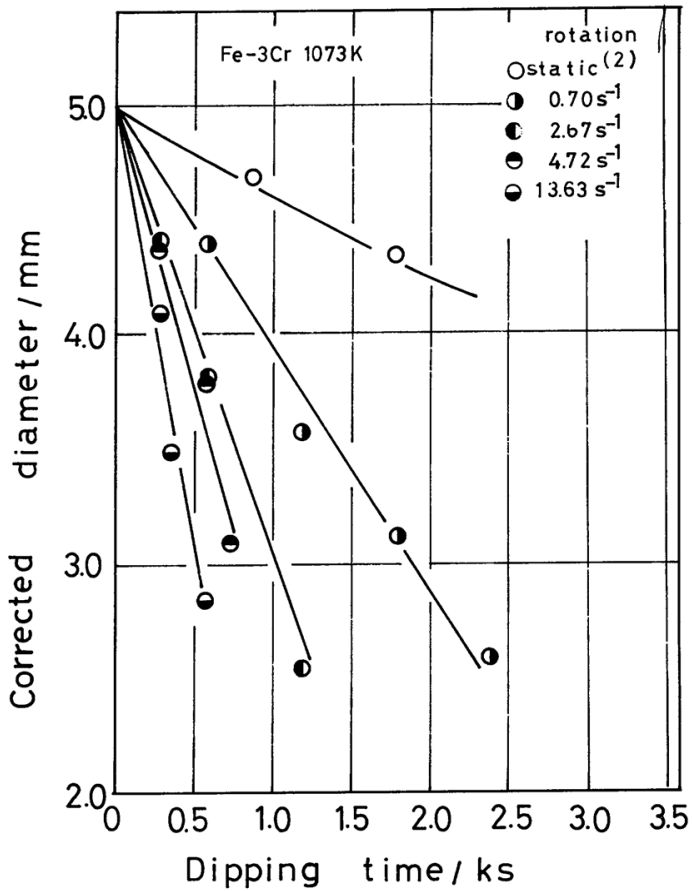

Fig. 6 Relation between corrected diameter and dipping time.

5. Dissolution process of each ferrous alloy

(1) Correlative equation of mass transfer under the forced flow

When dissolution of solid into liquid is controlled by the diffusion of solute element in the liquid, mass transfer between solid and liquid under the forced convection can be expressed by the following non-dimensional correlative equation:

$$
J_{D}=\left(k_{c} / u\right)(S c)^{a}=c .(R e)^{-b},
$$

where

$J_{D}: J_{D}$ factor

$k_{c}$ : mass transfer coefficient $(\mathrm{m} / \mathrm{s})$

$u$ : relative velocity between solid and liquid $(\mathrm{m} / \mathrm{s})$

Sc: Schmidt number $\left(S c=\mu / \rho_{1} D\right)$

$\operatorname{Re}:$ Reynolds number $\left(\operatorname{Re}=L_{d} u \rho_{1} / \mu\right)$

$a, b, c:$ constants

$L_{d}$ : characteristic length (m) (corrected diameter)

$\mu: \quad$ viscosity coefficient $(\mathrm{kg} / \mathrm{m} \cdot \mathrm{s})$ and

$\rho_{1}$ : density of liquid $\left(\mathrm{kg} / \mathrm{m}^{3}\right)$

$D:$ diffusion coefficient $\left(\mathrm{m}^{2} / \mathrm{s}\right)$
This non-dimensional correlative equation can be applied not only to flat plate and cylindrical models but also to various models such as rotated, oval, prismatic and cubic models. Furthermore, the equation can be used for liquid metal in the same manner as for usual viscous fluid ${ }^{(13)}$.

Various non-dimensional correlative equations as mentioned above were reported by experimental investigations on mass transfer between solid and liquid using a rotated cylinder. Typical examples are as follows:

$$
J_{D}=\left(k_{c} / u\right)(S c)^{0.644}=0.0791(R e)^{-0.30},
$$

where $R e=150-52000$ and $S c=835-11000$, for benzonic acid and -water and -glycerin by Eisenberg et al. ${ }^{(14)}$

$$
J_{D}=\left(k_{c} / u\right)(S c)^{0.60}=0.135(R e)^{-0.4},
$$

where $R e=200-2.5 \times 10^{5}$ and $S c=462-31200$, for benzonic acid -water and -sucrose solution by Bennet and Lewis ${ }^{(15)}$.

$$
J_{D}=\left(k_{c} / u\right)(S c)^{0.644}=0.112(R e)^{-0.330},
$$

where $R e \fallingdotseq 900-40000$,

for steel cylinder-molten iron $(\mathrm{Fe}-\mathrm{C})$ by $\mathrm{Kim}$ and Pelke ${ }^{(7)}$.

$$
J_{D}=\left(k_{c} / u\right)(S c)^{2 / 3}=0.12(R e)^{-0.31},
$$

where $R e=29-260$,

for solid $\mathrm{MgO}$-molten $\mathrm{Fe}_{t} \mathrm{O}-\mathrm{CaO}-\mathrm{SiO}_{2}$ slag by Umakoshi et al. ${ }^{(16)}$

$$
J_{D}=0.83 R e^{-0.5} \quad \text { (laminal flow region) }
$$

for solid lime-molten $\mathrm{CaO}-\mathrm{Al}_{2} \mathrm{O}_{3}-\mathrm{SiO}_{2}$ slag by Kawai $^{(17)^{\circ}}$.

Besides, the correlative equation for benzonic acid-water $(R e=50-34700, S c=942)$ was reported by Sherwood and Ryan ${ }^{(18)}$, which was in good agreement with that by Eisenberg et al. ${ }^{(14)}$

Smith and $\operatorname{Greif}^{(19)}$ reported the following correlative equation by a theoretical study:

$$
\begin{aligned}
S h= & 3 K \cdot 3^{2 / 1} / 2 \pi \cdot(f / 2)^{1 / 2} \\
& \cdot\left(S c / S c_{t}\right)^{1 / 3}(1+4 \beta / \operatorname{Re} \cdot 2 f)^{1 / 3},
\end{aligned}
$$

where

$S h$ : Sherwood number $\left(S h=L_{d} k_{c}^{\prime} / D\right)$

$k_{c}^{\prime}$ : mass transfer coefficient $(\mathrm{cm} / \mathrm{s})$

$K$ : constant $\left(7.47 \times 10^{-2}\right)$ 
$\beta:$ constant $(=5)$

$f:$ friction coefficient $\left(f / 2=0.079(R e)^{-0.30}\right)$ and

$S c_{t}$ : Schmidt number for turbulent flow $(=1.0)$ $J_{D}$ value can be obtained by changing this theoretical equation.

$J_{D}$ values calculated by the above correlative equations are plotted against $R e$ number. Then, the dissolution process of ferrous alloys can be discussed by comparing $J_{D}$ values obtained in this study, which is called $J_{\text {ob }}$ hereafter, with the calculated $J_{D}$ values.

\section{(2) Calculation of $\boldsymbol{J}_{\mathrm{ob}}$ values in this study}

In order to estimate $J_{\text {ob }}$ values, the apparent mass transfer coefficient $k_{\mathrm{ob}}$ (equivalent to $k_{c}$ or $k_{c}^{\prime}$ in the equations), the relative velocity $u$, Schmidt number $S c$ and the constant $a$ must be estimated, as shown in eq. (1).

As described by the static bath ${ }^{(2)}$, when the dissolution of solid specimen is controlled by mass transfer in molten metal, $k_{\mathrm{ob}}$ can be ob- tained by the following equation:

$$
\begin{aligned}
k_{\mathrm{ob}}= & -r_{1} \cdot \rho_{\mathrm{s}}\left(\mathrm{d} r_{1} / \mathrm{d} t\right) \\
& /\left(\% x_{1 \mathrm{~s}} \cdot \rho_{1 \mathrm{~s}} / 100-\% x \cdot \rho_{1} / 100\right) r_{2},
\end{aligned}
$$

where

$r_{1}:$ corrected radius (one-half of corrected diameter) (m)

$r_{2}$ : distance from the center of the specimen to the surface of the alloy layer (m)

$\% x$ : solute concentration in molten metal (mass $\%$ )

$\rho_{1}$ : density of molten metal $\left(\mathrm{kg} / \mathrm{m}^{3}\right)$

$\% x_{1 s}$ : saturated solute concentration in molten metal (mass \%)

and

$\rho_{1 \mathrm{~s}}$ : density of molten metal saturated with solute $\left(\mathrm{kg} / \mathrm{m}^{3}\right)$

The relative velocity $u(\mathrm{~m} / \mathrm{s})$ can be calculated by the equation, $u=2 \pi r_{2} R$, where $R$ is the rotating speed of specimen per second $\left(\mathrm{s}^{-1}\right)$.

The constant $a$ is $1 / 3-2 / 3$ for various models

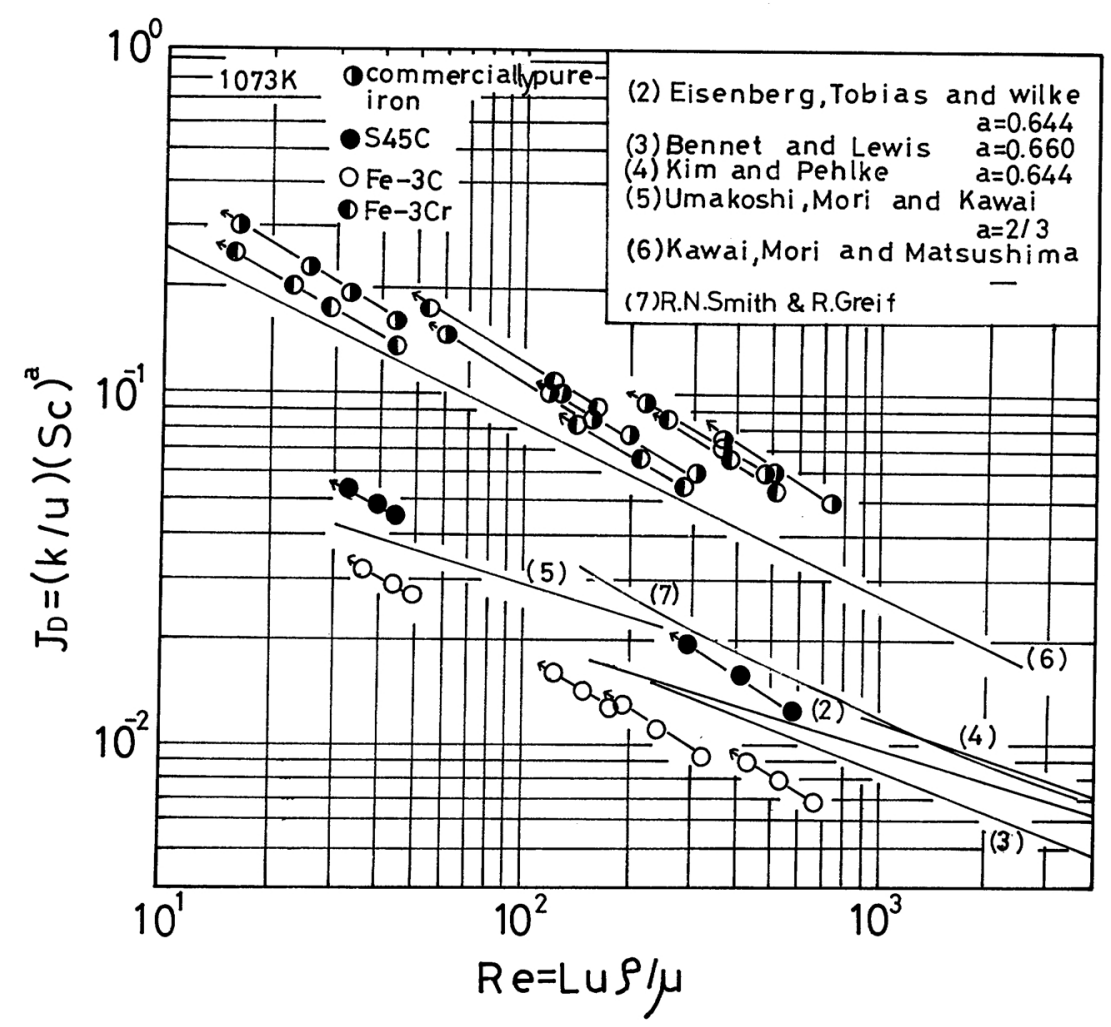

Fig. 7 Non-dimentional correlation of mass-transfer from rotated solid ferrous alloy into molten pure aluminium bath. 
and systems, and $a=2 / 3$ is adopted in this experiment.

The diffusion coefficient, the density and the viscosity of molten aluminium are required in order to calculate $S c$ number. The values used for the discussion on the static bath are adopted $^{(20)-(22)}$ for the calculation of $R e$ number in this study. For $\% x_{1 s}$, the value in the previous paper ${ }^{(23)}$ is also used.

\section{(3) Discussion on controlling step of dissolution of ferrous alloys}

$J_{\text {ob }}$ values obtained in this study are plotted against $R e$ number in Figs. 7 and 8. Figure 7 shows the results of commercially pure iron, $\mathrm{Fe}-3 \mathrm{C}$ and $\mathrm{Fe}-3 \mathrm{Cr}$ alloys at $1073 \mathrm{~K}$, and Fig. 8 shows the results of $\mathrm{Fe}-3 \mathrm{Si}$ at $1073 \mathrm{~K}$ and commercially pure iron at 1023 and $973 \mathrm{~K}$. The results of $\mathrm{S} 45 \mathrm{C}$ at $1073 \mathrm{~K}$ are given in both figures. The values obtained by the nondimensional correlative equation shown in 5.(1) are also given. The exponent of $S c$ number in $J_{D}$ factor is expressed by $a$. $J_{D}$ changes with time, and the time progress is expressed by the arrow. The exponent of $S c$ number in each equation is not always $2 / 3$, but this value may be used for the purpose of comparison and discussion, because the accuracy of each physical property is not high.

When the non-dimensional correlative equations shown in these figures are compared among one another, eqs. (2), (3), (4) and (5) are in good agreement, but eq. (6) gives a considerably higher $J_{D}$ value. Many other papers report the equations which are also in good agreement with eqs. (2), (3), (4) and $(5)^{(5)(24)(25) e t c .}$. Furthermore, these equations agree also with the theoretical correlative eq. (7). Therefore, eqs. (2)-(7) may be considered as the standard. If the experimental values agree with these equations, the dissolution of ferrous alloy can be considered to be controlled by the diffusion process that $\mathrm{Fe}$ atoms diffuse through the diffusion layer into bulk in molten pure

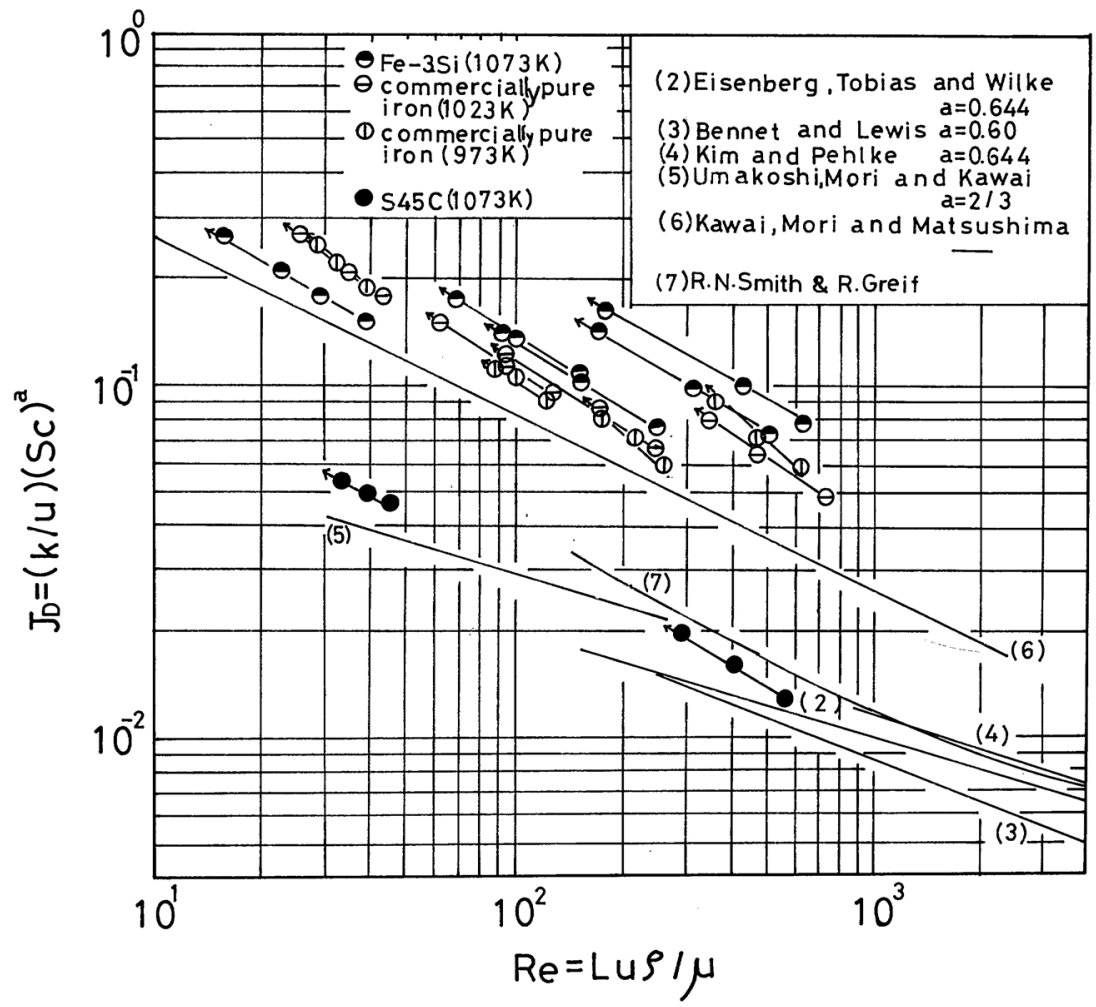

Fig. 8 Non-dimensional correlation of mass-transfer from rotated solid ferrous alloy into molten pure aluminium bath. 
aluminium. If the experimental values are considerably lower, processes such as the reaction at the interface between ferrous alloy layers, the diffusion process of $\mathrm{Fe}$ in the alloy layer and the formation process of alloy layer, or the reaction at the interface between alloy layer and molten aluminium are the controlling step of dissolution.

In this experiment, the alloy layers of commercially pure iron, $\mathrm{Fe}-3 \mathrm{Cr}$ and $\mathrm{Fe}-3 \mathrm{Si}$ alloys flaked off as mentioned above. Moreover, the rugged surface was observed for these specimens inside the alloy layers rotated at more than $2.67 \mathrm{~s}^{-1}$. But this phenomenon was not observed for $\mathrm{Fe}-3 \mathrm{C}$ alloy. Then a rather lower carbon alloy, S45C, was dipped and rotated, but the rugged surface was not observed on the alloy layer (Fig. 9) and also inside the alloy layer (Fig. 10). For S45C, $J_{\mathrm{ob}}$ was plotted against $R e$ number (Fig. 7 or Fig. 8), which agreed well with the non-dimensional correlative equations. When rotated at $0.70 \mathrm{~s}^{-1}, J_{\mathrm{ob}}$

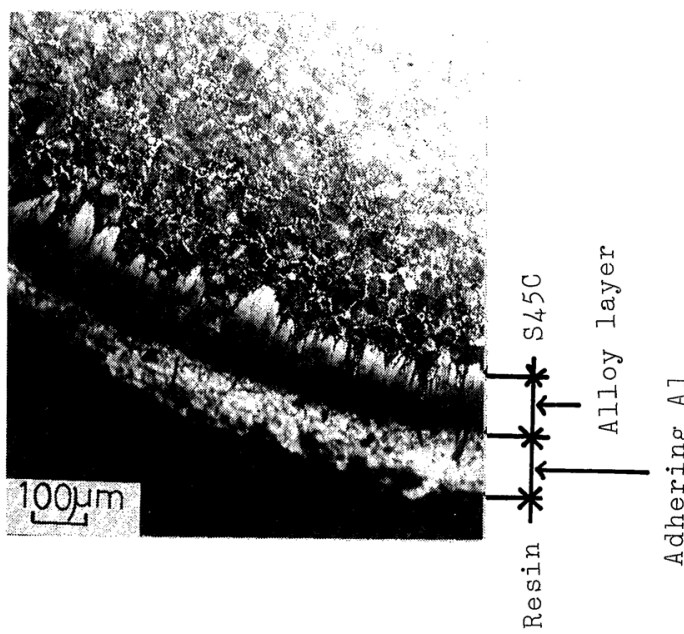

Fig. 9 Alloy layer formed on S45C rotated at $10.0 \mathrm{~s}^{-1}$ in molten pure aluminium at $1073 \mathrm{~K}$.

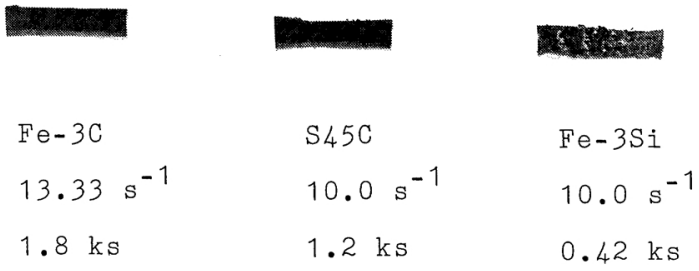

Fig. 10 Surface of the ferrous alloy inside the adhering aluminium and alloy layer. was slightly higher, which will be mentioned later.

\section{(a) Dissolution of $S 45 C$}

When $\mathrm{S} 45 \mathrm{C}$ was rotated at $10 \mathrm{~s}^{-1}$, as shown in Figs. 7 or $8, J_{\text {ob }}$ was in good agreement with the non-dimensional correlative equations. When rotated at $0.70 \mathrm{~s}^{-1}$, the specimen was more attacked at its upper portion than at its lower portion. This is an evidence of the effect of natural convection ${ }^{(2)(5)}$. Therefore, $J_{\text {ob }}$ at $0.70 \mathrm{~s}^{-1}$ can be considered to become greater than $J_{D}$ of the non-dimensional correlative equation. As $J_{\text {ob }}$ of $\mathrm{S} 45 \mathrm{C}$ is in good agreement with $J_{D}$ of the correlative equation, the dissolution of $\mathrm{S} 45 \mathrm{C}$ is considered to be controlled by the diffusion of $\mathrm{Fe}$ atoms in molten aluminium.

The mass transfer resistance or the chemical reaction resistance was considered to exist in the alloy layer for the dissolution of commercially pure iron and $\mathrm{Fe}-\mathrm{C}$ alloys $(2 \%$ and $3 \% \mathrm{C})$ in the static bath ${ }^{(2)}$. Hence, such a resistance can be also considered to exist in the alloy layer of $\mathrm{S} 45 \mathrm{C}$. But this is negligible because of considerably thin alloy layer. So, S45C can be considered as a standard for the discussion about the controlling step of dissolution of the other alloys.

\section{(b) Dissolution of commercially pure iron, $\mathrm{Fe}-3 \mathrm{Cr}$ and $\mathrm{Fe}-3 \mathrm{Si}$ alloys}

By the dissolution of commercially pure iron and $\mathrm{Fe}-3 \mathrm{Cr}$ alloy in the static bath ${ }^{(2)}$, it is clear that the alloy layer was thick, and the mass transfer resistance or the chemical reaction resistance was considered to exist in the alloy layer. However, the alloy layers become thinner for the rotated samples, and $J_{\mathrm{ob}}$ is much greater than $J_{D}$ of the non-dimensional correlative equation and $J_{\mathrm{ob}}$ of $\mathrm{S} 45 \mathrm{C}$. Therefore, in this case, the mass transfer resistance in the alloy layer can be considered negligible.

For $\mathrm{Fe}-3 \mathrm{Si}$ alloy, the mass transfer resistance or the chemical reaction in the alloy layer could be neglected in the static bath. Moreover, when rotated, $J_{\mathrm{ob}}$ of dissolution is greater than $J_{D}$ and $J_{\mathrm{ob}}$ of $\mathrm{S} 45 \mathrm{C}$. Therefore, for this alloy, the mass transfer or the chemical reaction resistance in the alloy layer can be considered negligible. 
As mentioned above, the dissolution of commercially pure iron, $\mathrm{Fe}-3 \mathrm{Cr}$ and $\mathrm{Fe}-3 \mathrm{Si}$ alloys under the rotation is considered to be controlled by diffusion of $\mathrm{Fe}$ atoms in molten aluminium. However, $J_{\mathrm{ob}}$ values of these alloys are considerably larger. So, a factor, which accelerates the dissolution, must be considered, other than the decrease of thickness of the alloy layer by the rotated specimen.

As mentioned above, by these alloys, some trace of flaking of the alloy layer is observed at every rotating speed. Moreover, for rotating speed $0.70 \mathrm{~s}^{-1}$, the effect of natural convection is recognized. At higher speed, the surface inside the alloy layer become rugged, and this tendency becomes more noted with increasing speed. This ruggedness is more remarkable for $\mathrm{Fe}-3 \mathrm{Si}$ alloy than for commercially pure iron and $\mathrm{Fe}-3 \mathrm{Cr}$ alloy at rapid rotation. Therefore, the rugged surface may be considered as the trace of erosion of the ferrous alloys by molten aluminium. Furthermore, it can be also suspected that a local turbulent condition in the preferentially dissolved region or a mutual effect of turbulent flow in the eroded region becomes remarkable with increasing rotating speed.

The dissolution process will be discussed now by contrasting this phenomenon with $J_{\mathrm{ob}}$ values. $J_{\text {ob }}$ values at a low rotating speed become very large, when the dissolution is accelerated by the nautral convection or flaking of the alloy layer. As rotating speed increases, $J_{\mathrm{ob}}$ values of $\mathrm{Fe}-3 \mathrm{Si}$ alloy become larger than those of commercially pure iron and $\mathrm{Fe}-3 \mathrm{Cr}$ alloy. The tendency is in agreement with the increasing ruggedness. Therefore, at a high rotating speed, the dissolution may be accelerated by flaking of the alloy layer and erosion of the ferrous alloy by molten aluminium or by local turbulent condition on the rugged site.

\section{(c) Dissolution of $\mathrm{Fe}-3 \mathrm{C}$ alloy}

$J_{\text {ob }}$ of $\mathrm{Fe}-3 \mathrm{C}$ alloy was slightly smaller than that of S45C. Hence, the mass transfer resistance or the chemical reaction resistance in the alloy layer can be considered to exist. Rotation of the specimen decreases the thickness of the alloy layer considerably, and the mass transfer resistance in the alloy layer decreases some- what, but not negligibly. The chemical reaction resistance may exist at the interface of $\mathrm{Fe}-3 \mathrm{C}$ alloy and alloy layer, because of the existence of much eutectic cementite. Therefore, for the dissolution of $\mathrm{Fe}-3 \mathrm{C}$ alloy, a little mass transfer or chemical reaction resistance can be considered to exist in the alloy layer.

\section{Conclusion}

In order to study the dissolution of ferrous alloys into molten aluminium under the forced flow, commercially pure iron, $\mathrm{S} 45 \mathrm{C}, \mathrm{Fe}-3 \mathrm{Cr}$, $\mathrm{Fe}-3 \mathrm{Si}$ and $\mathrm{Fe}-3 \mathrm{C}$ alloys were dipped and rotated in molten pure aluminium, and the dissolution process of each ferrous alloy was examined. The following results were obtained.

(1) The alloy layer becomes thinner with increasing rotating speed, and the thickness is constant for various dipping times. The shape of the alloy layers formed on commercially pure iron, $\mathrm{Fe}-3 \mathrm{Cr}$ and $\mathrm{Fe}-3 \mathrm{Si}$ alloys changes from tongue-like to band-like, as the rotating speed increased. For Fe-3C alloy, the alloy layer is band-like with a slightly tongue-like tip at every rotating speed.

(2) With regard to the composition of the alloy layer, $\mathrm{Fe}_{2} \mathrm{Al}_{5}$ occupies the major portion in the same manner as under the static condition.

(3) The dissolution rate of each alloy into molten pure aluminium increases with increasing rotating speed. The corrosion resistance against molten aluminium is the highest for $\mathrm{Fe}-3 \mathrm{C}$ alloy and the lowest for Fe-3Si alloy. This result agrees with the tendency in the static bath.

(4) The dissolution of commercially pure iron, $\mathrm{S} 45 \mathrm{C}, \mathrm{Fe}-3 \mathrm{Cr}$ and $\mathrm{Fe}-3 \mathrm{Si}$ alloys is controlled by the mass transfer of $\mathrm{Fe}$ in molten aluminium. At lower rotating speed the dissolution is accelerated by natural convection and flaking of the alloy layer, while at higher rotating speed the dissolution is accelerated by flaking of the alloy layer and erosion by molten aluminium or by turbulent flow at the rugged site on the alloy surface.

In the alloy layer of $\mathrm{Fe}-3 \mathrm{C}$ alloy, there may be a little mass transfer or chemical reaction resistance in the molten aluminium under the 
forced flow condition as well as under the static condition.

\section{Acknowledgements}

The authors wish to thank Kobe Steel Co., Ltd. for help in manufacture of the rotary apparatus and chemical analysis and also for kind supply of aluminium, and Pacific Metals Co., Ltd. for kind supply of commercially pure iron. Moreover, they are grateful to Dr. M. Sano, Assistant Professor of Faculty of Engineering, Nagoya University, who gave useful advice and kind assistance for the preparation of this paper.

\section{REFERENCES}

(1) M. Niinomi and Y. Ueda: Trans. JIM, 23 (1982), 709.

(2) M. Niinomi, Y. Ueda and M. Sano: Trans. JIM, 23 (1982), 780.

(3) Y. Ueda and M. Niinomi: J. Japan Foundrymen's Soc., 50 (1978), 549 (in Japanese).

(4) M. Kosaka and S. Minowa: J. Iron Steel Inst. Japan, 53 (1967), 983 (in Japanese).

(5) M. Kosaka and S. Minowa: J. Iron Steel Inst. Japan, 52 (1966), 1748 (in Japanese).

(6) H. Nomura and K. Mori: J. Iron Steel Inst. Japan, 55 (1969), 1134 (in Japanese).

(7) Yeng.U Kim and R. D. Pelke: Met. Trans., 5 (1974), 2527.

(8) T. Sakurai and K. Mori: J. Iron Steel Inst. Japan,
62 (1976), S568 (in Japanese).

(9) S. Minowa and M. Kosaka: J. Iron Steel Inst. Japan, 50 (1964), 56 (in Japanese).

(10) J. A. Leak: Acta Crystallogr, 17 (1964), 56.

(11) M. Hansen: Constitution of Binary Alloys, McGraw-Hill, (1958), p. 90.

(12) K. Nishida and T. Narita: J. Japan Inst. Metals, 35 (1970), 269 (in Japanese).

(13) A. Hirata: Chemical Engineering, 28 (1964), 102 (in Japanese).

(14) M. Eisenberg, C. W. Tobias and C. R. Wilke: Chem. Eng. Prog. Symp. Series, 51 (1953), 1.

(15) J. A. R. Bennet and J. B. Lewis: AIChE Journal, 4 (1958), 418.

(16) M. Umakoshi, K. Mori and Y. Kawai: J. Iron Steel Inst. Japan, 62 (1976), S570 (in Japanese).

(17) Y. Kawai: Tetsuyakin-Hanno-Sokudo-Ron, Nikkan-Koogyo-Shinbun-Sha, (1973), p. 142 (in Japanese).

(18) T. K. Sherwood and J. M. Ryan: C. E. S., 11 (1959), 81

(19) R. N. Smith and R. Greif: Trans. ASME, J. Heat Transfer, 97 (1975), 594.

(20) J. F. Elliot and M. Gleiser: Therm. Chemistry for Steelmaking, Addison-Wesley, Vol. I, (1960), 7.

(21) T. P. Yao and V. Kondic: J. Inst. Metals, 81 (1952/53), 17.

(22) K. Uemura: J. Iron Steel Inst. Japan, 25 (1939), 24 (in Japanese).

(23) Metal Handbook, 8th edition, ASM, (1973), 260.

(24) I. Cornett and R. Kappesser: J. Electrom. Soc., 118 (1971), 1957.

(25) R. A. Seban and H. A. Johnson: NASA Memorandom (1959), 4-22-59W. 